\title{
CUESTIONES PROCESALES DEL PROCEDIMIENTO MONITORIO REGULADO EN EL CÓDIGO DEL TRABAJO Y LA FORMA DE PROCEDER EN LOS CASOS DE APLICARSE LAS NORMAS SOBRE.RÉGIMEN DE SUBCONTRATACIÓN
}

\author{
FERNANDO ORELLANA TORRES \\ Universidad Católica del Norte
}

\begin{abstract}
RESUMEN: Se presenta la función y estructura del procedimiento monitorio, para luego centrarse en la particularidad de su iniciación (496 CT), vale decir, el requisito de comparendo previo ante la Inspección del Trabajo, en base a ello y desde la perspectiva del debido proceso, se estudia la problemática de las responsabilidades contempladas en el régimen de subcontratación, concluyéndose que es necesario que los terceros subsidiaria o solidariamente obligados sean oídoș también en la etapa administrativa.
\end{abstract}

Palabras clave: Procedimiento monitorio, debido proceso, audiencia de conciliación, inspección del trabajo, bilateralidad de la audiencia, subcontratación.

ASTRACT: We present the role and structure of monitor procedure, and then focus on the particularity of its initiation (Article 496 of the Labor Code), id est, the requirement of previous appearing before the Labor Inspection, and on this basis and from the standpoint of due process, we study the problem of the responsibilities contemplated in the outsource scheme, concluding that it is necessary that third parties, subsidiary or jointly required, will be heard also in the administrative stage.

Key words: monitor procedure, due process, conciliation audience, Labor Inspection, outsource, bilateralidad de la audiencia.

\section{APLICACIÓN DEL PROCEDIMIENTO MONITORIO}

El Código del Trabajo -en adelante CT-'regula_en-sus artículos 496 a 502 el procedimiento monitorio ${ }^{1}$, proceso que se aplica a las contiendas cuya cuantía sea igual o inferior a 10 ingresos mínimos mensuales, sin considerar, en su caso, los aumentos a que hubiere lugar por aplicación del artículo 162 -incisos quinto y séptimo-. Además, tiene aplicación este procedimiento a las contiendas a que se refiere el artículo $201 \mathrm{del} \mathrm{CT}$.

El procedimiento monitorio, por lo tanto, tiene dos causas de aplicación:

a) Contiendas ${ }^{2}$ donde se acciona por una determinada cuantía. Esta cuantía está expresamente indicada en el inciso primero del artículo 496 sea igual o inferior a diez ingresos mínimos mensuales.

\footnotetext{
* Abogado. Profesor de Derecho Procesal, Escuela de Derecho, Universidad Católica del Norte (Antofagasta). DEA y Candidato a Doctor en Derecho Procesal por la Universidad de Zaragoza, España. Abogado (1995).

1 Sobre los aspectos fundamentales de todo Procedimiento Monitorio véase PÉREZ RAGONE, A. "En torno al procedimiento monitorio desde el derecho procesal comparado europeo", en: Revista de Derecho vol. 19, n. 1. Valdivia: Universidad Austral, 2006, pp. 205-235. Los aspectos históricos se pueden ver en LAURIE COFRÉ, M. El proceso monitorio, un nuevo proceso civil para el derecho chileno. Tesis. Antofagasta: Universidad Católica del Norte, 2007.

${ }^{2} \mathrm{Al}$ expresar el vocablo "contiendas" puede referirse a aquellas generadas del término de la relación laboral o aquellas prestaciones adeudadas de una relación laboral vigente.
} 
b) Contienda del artículo 201 del CT. El artículo 201 del CT, en su inciso primero comienza haciendo referencia al artículo 174 del mismo cuerpo legal, que reglamenta el desafuero laboral, pero lo cierto es que esta remisión no tiene más alcance que servir de fundamento al derecho de la trabajadora para reclamar su reincorporación y/o el pago de las remuneraciones por todo el tiempo que haya permanecido indebidamente fuera del trabajo, en caso de haber sido despedida por ignorancia, precisamente, de su calidad de trabajadora aforada. El artículo 201 del CT, no se pone en la hipótesis de requerir previamente a la justicia la autorización para despedir a un trabajador con fuero laboral, sino que todo lo contrario, se coloca en el evento de despido sin que haya mediado desafuero previo. En este contexto, resulta lógico y coherente, que una materia tan sensible y trascendente como es la protección a la maternidad, frente a un despido, requiera de una actuación rápida y eficaz por parte de la judicatura a través del procedimiento monitorio incluso sin tener que cumplir con la exigencia de acudir previamente ante la Inspección del Trabajo, como expresamente lo previene el artículo $497^{3}$ del CT.

Por expresa mención del artículo 497 del CT, previo al inicio de la acción judicial monitoria cuando lo que se reclama es la cuantía -y no el caso del artículo 201-, es necesario que se haya reclamado ante la Inspección del Trabajo ${ }^{4}$, la que debe fijar día y hora para la realización del comparendo respectivo, al momento de ingresarse dicho reclamo, haciendo las citaciones que correspondan.

\section{PRESUPUESTOS DE TODO PROCEDIMIENTO MONITORIO Y SUS REQUISITOS}

De lo dicho debemos concluir en esta parte que el procedimiento monitorio exige los siguientes presupuestos:

1. Una contienda, un conflicto laboral. Ya lo dijimos con anterioridad, esta contienda puede generarse con ocasión del término de la relación laborạl o de una relación laboral vigente 5 .

\footnotetext{
3 WALter DIAZ y LANATA FUenZalidA. Regimen Legal del nuevo proceso laboral chileno. Santiago: Legal Publishing, 2009, pp. 287-288

${ }^{4}$ Así también lo ha resuelto la Jurisprudencia de nuestros tribunales. "cabe tener presente que para deducir demanda judicial en procedimiento monitorio el trabajador, en conformidad a lo establecido en el artículo 497 del Código del Trabajo, debe deducir reclamo ante la Inspección del Trabajo, debiendo al efecto fijarse día y hora para la audiencia respectiva, lo que debe hacer el servicio fiscalizador al momento de ingresarse el reclamo... Que como se advierte de la citada disposición, el único requisito formal para interponer la correspondiente acción judicial, es el hecho de que el trabajador haya deducido la reclamación administrativa, lo que se explica en cuanto la ley promueve la solución extrajudicial de las controversias "especialmente cuando estas son de cuantía menor (Corte de Apelaciones de Chillán, 5 de enero 2010). En contra Ilustrísima Corte de Apelaciones de Concepción, 26 de mayo 2010: Que, como ya lo ha resuelto esta Corte (sentencia de 10 de agosto de 2009, en autos rol 9-2009), no constituye un requisito de procesabilidad del procedimiento monitorio el emplazamiento ante la Inspección del trabajo del demandado solidario, porque el artículo 497 del Código del Trabajo se refiere al empleador, y, además, no se afectan las normas del debido proceso, puesto que tiene la oportunidad de hacer valer su defensa en la contestación de la demanda, lo que ocurrió en la especie, en virtud de lo cual se recibió la causa a prueba, rindiéndose la correspondiente por las partes y resuelta la controversia en la sentencia. Por consiguiente, no existe la infracción que reclama el recurrente".

5 Pereira Lagos. El procedimiento monitorio laboral. Santiago: Legal Publishing, 2010, pp. 41-43.
} 
2. Que esta contienda sea por una cuantía igual o inferior a 10 ingresos mínimos mensuales, $\mathrm{O}$ se refiera al caso del artículo $201 \mathrm{del} \mathrm{CT}$.

Pero si lo que se pretende ejercer es la acción monitoria por cuantía igual o inferior a 10 ingresos mínimos mensuales es necesario además cumplir con los siguientes requisitos:

1. Que se deduzca reclamo ante la Inspección del Trabajo.

2. Que la Inspección del Trabajo fije día y hora para la realización de un comparendo de conciliación, y

3. Que el reclamante (trabajador) concurra al comparendo de conciliación.

Los tres requisitos anteriores se deducen de los artículos 497 y 498 del CT.

Es perentoria la primera norma al exigir, en su inciso primero, que previo al inicio de la acción de la acción judicial se deduzca reclamo ante la Inspección del Trabajo. Y luego expresa que al momento de ingresar la reclamación debe fijar día y hora para un comparendo de conciliación.

Por su parte, el artículo 498 se pone en la situación que el reclamante (trabajador) no concurra al comparendo estando legalmente citado. En este caso se deben archivar los antecedentes y puede accionar judicialmente pero ya no monitoriamente sino en conformidad a las reglas del procedimiento de aplicación general de los artículos 446 y siguientes del CT.

\section{PROCEDIMIENTO ANTE LA INSPECCIÓN DEL TRABAJO. COMPARENDO DE CONCILIACIÓN. PRESUPUESTO DEL PROCEDIMIENTO MONITORIO}

La intervención de la Inspección del Trabajo ya no es parte del procedimiento monitorio, pero veremos que es un elemento indispensable para accionar monitoriamente en los casos del artículo 496 primera parte.

En lo que respecta al comparendo de conciliación ante la Inspección del Trabajo correspondiente -que como hemos dicho es un trámite esencial ${ }^{6}$ a fin de poder ejercer con posterioridad la acción monitoria por cuantía igual o inferior a 10 ingresos mínimos mensualesdebemos señalar que no puede ser ordenado de oficio por la Inspección, porque el legislador

\footnotetext{
${ }^{6}$ Opinión contraria encontramos en el siguiente fallo "Que como se advierte de la citada disposición, el único requisito formal para interponer la correspondiente acción judicial, es el hecho de que el trabajador haya deducido la reclamación administrativa, lo que se explica en cuanto la ley promueve la solución extrajudicial de las controversias "especialmente cuando estas son de cuantía menor, pero no puede ello extenderse al hecho de que se haya citado efectivamente al reclamado o se haya efectuado la audiencia administrativa, no solo en tanto no lo exige la ley, sino considerando además los exiguos plazos que contempla para que el trabajador pueda deducir las correspondientes acciones judiciales. Plantear como exigencia que se cite al empleador o al demandado solidario en virtud del reclamo administrativo ante la Inspección del Trabajo, limita el derecho a defensa establecido en el numeral tercero del artículo 19 de la Constitución Política de la República y podría importar un perjuicio para el trabajador, desde que con el transcurso del tiempo, sin que proceda a la tramitación íntegra del reclamo, podrían vencer los plazos para ejercer las acciones judiciales correspondientes" -Corte de Apelaciones de Chillán, 5 de enero 2010-
} 
exige que el trabajador previamente deduzca reclamo. Una vez ingresado el reclamo la inspección debe fijar día y hora para el comparendo.

La citación al comparendo, según el artículo 497, se hace por carta certificada, que de acuerdo con el artículo 508, va dirigida al domicilio que las partes hayan fijado en el contrato de trabajo. Esta notificación se entiende practicada al sexto día hábil contado desde la fecha de su recepción por la Oficina de Correos respectiva. Pero el artículo 497 también permite que la notificación al comparendo sea realizada por funcionario de la Inspección quien actúa en calidad de ministro de fe, para todos los efectos legales. En esta situación, la notificación al empleador se materializa personalmente o se entrega a persona adulta que se encuentre en el domicilio del reclamado.

De lo señalado podemos expresar que la citación al comparendo de conciliación es un elemento esencial para que las partes - reclamante (trabajador) y reclamado (empleador) - tomen conocimiento del llamamiento al comparendo y de su objeto -la conciliación-. Y permite además que el empleador tome conocimiento de la existencia de un reclamo por parte del trabajador que pretende obtener con celeridad el pago de una suma adeudada.

Además, para respetar un principio fundamental en materia administrativa y procesal, como lo es el de la bilateralidad, exige que la citación se haga en conformidad a la ley -carta certificada o mediante funcionario que tiene la calidad de ministro de fe- y en el caso que la citación la realice el funcionario de la Inspección se debe hacer al empleador personalmente, entregándose esta citación al propio empleador o a una persona adulta que se encuentre en el domicilio del reclamada.

Una vez citados en conformidad a la ley -el trabajador y el empleador- habrá que esperar que llegue el día del comparendo de conciliación.

Las partes deben concurrir al comparendo citado con los instrumentos probatorios que se dispongan, tales como contrato de trabajo, balances, comprobantes de remuneración, registros de asistencia y cualesquiera otros que estimen pertinentes. La presentación de estos documentos son de suma importancia porque de acuerdo con el inciso final del artículo 499 del CT si el trabajador demanda monitoriamente debe acompañar el acta levantada en el comparendo y los documentos presentados en el comparendo, documentos que pueden haber sido presentados por el trabajador y por el empleador. Obviamente que el trabajador no acompañará los documentos del empleador porque no estarán en su poder, pero es fundamental tener presente lo señalado, para que el juez acoja inmediatamente o no la demanda monitoria de conformidad con el artículo 500 del CT, porque si el juez analiza la documentación presentada por el trabajador y en el acta se dejó constancia de los documentos presentados por el empleador, el juez del trabajo deberá rechazar de plano la demanda o bien en caso de no existir antecedentes suficientes para su pronunciamiento citará a las partes a la audiencia de conciliación, contestación y prueba.

Llegado el día del comparendo pueden producirse las siguientes situaciones:

a) Concurren ambas partes: si concurre el reclamante y el reclamado pueden llegar a una conciliación total o parcial, o bien no llegar a acuerdo. Si la conciliación es parcial o no llegan a acuerdo se debe aplicar el artículo 499 del CT que determina que en estos 
casos el trabajador puede interponer demanda (aun cuando no lo dice debemos entender que es la demanda monitoria) ante el juez del trabajo competente dentro de los plazos de los artículos 168 y 201 del CT.

b) Solo concurre el reclamante: se debe aplicar el artículo 499 del CT que determina que en estos casos el trabajador puede interponer demanda -aun cuando no lo dice debemos entender que es la demanda monitoria- ante el juez del trabajo competente dentro de los plazos de los artículos 168 y 201 del CT.

c) No concurre el reclamante: se debe aplicar en este caso el artículo $498 \mathrm{del}$ CT. Se pone término al comparendo, debiendo archivarse los antecedentes. Y, de acuerdo con el inciso segundo, el trabajador puede accionar judicialmente conforme a las reglas del procedimiento de aplicación general, pero no accionar monitoriamente. Nótese que no tiene trascendencia en esta situación que el empleador haya concurrido o no al comparendo.

\section{PROCEDIMIENTO ANTE EL JUEZ DEL TRABAJO. DEMANDA. RECLAMO. AUDIENCIA ÚNICA DE CONCILIACIÓN, CONTESTACIÓN Y PRUEBA}

El procedimiento monitorio laboral es especial, breve y concentrado y fue establecido en beneficio del trabajador, y no del empleador, aserto que se ratifica por el hecho que el inciso segundo del artículo 498 del CT deje a salvo al trabajador el ejercicio de acciones en procedimiento de aplicación general, y que el artículo 499 del CT expresa que el trabajador podrá interponer demanda ante el Tribunal competente dentro de los plazos de los artículos 168 y $201 \mathrm{del} \mathrm{CT}$.

El procedimiento monitorio ante el juez laboral se inicia con la demanda monitoria, y si estamos frente al caso de la acción por cuantía igual o inferior a 10 ingresos mínimos mensuales, es requisito necesario que el trabajador acompañe el acta levantada en el comparendo de conciliación celebrado ante la Inspección del Trabajo, y los documentos presentados en este.

Son diversas las situaciones que permite el legislador una vez presentada la demanda y declarada admisible:

1. Que el juez estime infundadas las pretensiones del demandante, caso en que las rechazará de plano. Dicha resolución permite ser recurrida.

2. En caso que el juez laboral estime fundadas las pretensiones monitorias del demandante, las acogerá inmediatamente mediante resolución judicial -sentencia- que debe ser notificada a las partes. La notificación al demandado se practica personalmente o conforme a las reglas de las notificaciones. En todo caso, en la notificación se hará constar los efectos que producen la falta de reclamo o su presentación extemporánea. Las partes solo pueden reclamar de la resolución dentro del plazo de 10 días hábiles contado desde su notificación, sin que proceda en contra de ella ningún otro recurso. Si el empleador reclama parcialmente de la resolución que acoge las pretensiones del trabajador, se aplica lo establecido en el artículo 462 del CT, es decir, debe certificarse por el tribunal de oficio la firmeza de aquello en que el empleador no se opuso, y si no pagare dentro de 5 días se da inicio a la ejecución. 
Para pronunciarse el tribunal sobre la demanda monitoria, debe considerar, entre otros antecedentes, la complejidad del asunto que se somete a su decisión, la comparecencia de las partes en la etapa administrativa y la existencia de pagos efectuados por el demandado. En caso de no existir antecedentes suficientes para este pronunciamiento, el tribunal debe citar a una audiencia de conciliación y prueba ${ }^{7}$.

Nótese que si no se reclama dentro del plazo de 10 días, o siendo la reclamación del empleador "parcial", se debe certificar de oficio la firmeza de la resolución judicial que acogió la pretensión monitoria, resolución judicial que a nuestro parecer es una sentencia definitiva condenatoria, que "crea" un título ejecutivo. Esta es la nota característica de los procesos monitorios: la creación de un título ejecutivo de forma inmediata en aquellos casos en que el acreedor demandante -trabajador en nuestro caso- tiene un crédito claramente fundado que de reclamarse judicialmente, a juicio del legislador el deudor nada tendría que oponer o la oposición sería mínima. El legislador quiere proporcionar al trabajador lo más rápidamente posible un título ejecutivo.

3. Presentada la reclamación -generalmente por el empleador- dentro del plazo de 10 días, o en el caso de no haber antecedentes suficientes para el pronunciamiento, el juez laboral citará a las partes a una audiencia única de conciliación y prueba, la que debe celebrarse dentro de los 15 días siguientes a su presentación.

Esta reclamación del empleador -como lo hemos escrito- es un caso de medio de impugnación en que se manifiesta la existencia de intereses contrapuestos y, por lo tanto, el legislador exige la concreción de una audiencia de "conciliación" para poder solucionar el conflicto generado, y de "prueba" para el evento de que no haya conciliación, se acrediten las respectivas pretensiones ${ }^{8}$. Con. la reclamación del empleador nace un proceso declarativo -dentro dél procedimiento monitorio- en el que el juez laboral deberá declarar si lo pretendido por el trabajador es procedente o no. Si es procedente pronuncia una sentencia definitiva de condena: título ejecutivo. Si no es procedente lo que reclama el trabajador pronuncia una sentencia de absolución a favor del empleador. Ambas producen cosa juzgada.

Las partes deben asistir a la audiencia con todos sus medios de prueba y, en caso de comparecer a través de mandatario, este deberá estar expresamente revestido de la facultad de transigir. La audiencia tiene lugar con solo la parte que asista.

El juez debe dictar sentencia al término de la audiencia, la que debe contener las menciones señaladas en los números 1, 2, 5, 6 y 7 del artículo 459 del CT. Atendida la naturaleza del procedimiento, no es necesario que la sentencia deba contener, por lo tanto, los requisitos de los números 3 y 4 del artículo 459 del CT, esto es, no es necesario que cuente con una síntesis de los hechos y de las alegaciones de las partes y el análisis de toda la prueba rendida, los hechos que estime probados y el razonamiento que conduce a esta estimación. Sin embargo, es preciso tener presente que

\footnotetext{
${ }^{7}$ CANDIa GuZMÁN y KoCH Cid. Reforma Procesal del Trabajo. Santiago: Editorial Metropolitana, 2009, p. 219.

${ }^{8}$ Orellana TORRes. Comentarios al nuevo proceso laboral. Santiago: Librotecnia, 2009, p. 275.
} 
el citado artículo 501 solo omite referirse a los No 3 y 4 del artículo 459 del CT. Por lo que debemos pensar que parece prohibirlo tácitamente. Sin embargo, de la misma normativa laboral como de la normativa constitucional, debemos concluir de una manera contraria por las siguientes razones: i) En cuanto a la valoración de la prueba, materia que no regula el procedimiento monitorio el artículo 432 del CT, en lo pertinente, dispone que al procedimiento monitorio, regulado en el párrafo $7^{\circ}$, se aplicará supletoriamente, en primer lugar, las normas del procedimiento de aplicación general contenida en su párrafo $3^{\circ}$. En este último, contenido en el párrafo citado, se dispone en el artículo 456 que el tribunal apreciará la prueba conforme a las reglas de la sana crítica. Esta obligación obliga a fundar la sentencia. ii) El artículo 19 No 3 , inciso $4^{\circ}$, de la Constitución Política de la República dispone que: Toda sentencia de un órgano que ejerza jurisdicción debe fundarse en un proceso previo legalmente tramitado. Corresponderá al legislador establecer siempre las garantías de un procedimiento y una investigación racionales y justos. Por su lado, el artículo 76, inciso primero, de la misma Carta Magna ordena que: La facultad de conocer de las causas civiles y criminales, de resolverlas y de hacer ejecutar lo juzgado, pertenece exclusivamente a los tribunales establecidos por la ley. Ni el Presidente de la República ni el Congreso pueden, en caso alguno, ejercer funciones judiciales, avocarse a causas pendientes, revisar los fundamentos o tenido de sus resoluciones o hacer revivir procesos fenecidos. Por lo tanto, debemos decir que no puede haber un proceso racional y justo sin una sentencia motivada.

\section{EL PROCEDIMIENTO MONITORIO Y EL RÉGIMEN DE SUBCONTRATACIÓN}

Se entiende como trabajo en régimen de subcontratación aquel realizado por un trabajador para un empleador, denominado contratista o subcontratista, quien ejecuta obras o faenas por cuenta y riesgo propio para una empresa principal, dueña de la obra o faena. Así, es requisito fundamental para que proceda el trabajo en régimen de subcontratación, que la empresa principal sea la dueña de la obra, empresa o faena en que se desarrollen los servicios o se ejecuten las obras objeto de la subcontratación?

La faena del personal subcontratado debe corresponder a actividades que pertenezcan a. la organización de la empresa principal y que estén sometidas a su dirección, debiendo por lo tanto, excluirse de tal aplicación, a aquellas que no cumplan tal exigencia.

El proceso monitorio el cual ha sido explicado en la primera parte de este trabajo tiene por objeto obtener a través de una vía judicial rápida, una vez agotada la vía ante la Inspección del Trabajo, el pago de una suma de dinero que no exceda de 10 ingresos mínimos mensuales, sin considerar los aumentos legales ${ }^{10}$.

Pero esta vía judicial es un procedimiento jurisdiccional que está legalmente regulado, y que en virtud del artículo 45 del CT se rige por los principios que expresamente señala

\footnotetext{
9 PALAVECINO CACERES. Subcontratación. Régimen Juridico del trabajo subcontratado y del suministro del personal -reimpresión-. Santiago: Editorial Jurídica de Chile, 2010.

10 Pereira Lagos, op. cit. (n. 5), p. 54.
} 
Fernando Orellana Torres / Cuestiones procesales del procedimiento monitorio regulado en el Código del Trabajo ...

"los procedimientos del trabajo serán orales, públicos y concentrados. Primarán en ellos los principios de la inmediación, impulso procesal de oficio, celeridad, buena fe, bilateralidad de la audiencia y gratuidad".

Estos principios formativos del proceso, obligan al juez y a las partes, y su cumplimiento constituye el instrumento que permite realizar el mandato constitucional contenido en el número $3^{\circ}$ del artículo 19 de la Carta Fundamental, dando forma al debido proceso.

Conforme lo señala el artículo 19 No 3 de la Constitución Política de la República "Toda sentencia de un órgano que ejerza jurisdicción debe fundarse en un proceso previo legalmente tramitado. Corresponde al legislador establecer siempre las garantías de un procedimiento y una investigación racionales y justos".

El principio de la bilateralidad de la audiencia supone, por lo tanto, darle a las partes igual posibilidad de ejercicio de sus facultades en el procedimiento, a través de toda la sucesión de actos que lo componen, de forma tal que gocen de igualdad de condiciones para expresarse y ser escuchados. Y en el caso del procedimiento monitorio esta sucesión de actos no se inicia con la demanda monitoria, porque como lo hemos indicado, el procedimiento monitorio cuando tiene su origen en una contienda cuya cuantía es igual o inferior a 10 ingreso mínimos mensuales, se inicia con el reclamo interpuesto en la Inspección del Trabajo, como lo indica el artículo 497 del CT. Por lo dicho, el principio de bilateralidad de la audiencia -en este caso del monitorio- supone el ejercicio de las facultades de las partes en el procedimiento ante la Inspección del Trabajo y ante el Juez de Letras del Trabajo. Esto es así, porque el propio artículo 497 del CT exige que se notifique al empleador a fin de que concurra al comparendo con los instrumentos probatorios, y en base a los documentos presentados por ambas partes la Inspección pueda llamar a éstas a conciliación.

De lo dicho debemos concluir que el demandado -empleador- en el procedimiento monitorio, necesariamente tiene que haber sido notificado legamente para el comparendo de conciliación, independiente de su asistencia o no al comparendo. En virtud de esta citación será considerado parte en el procedimiento ante el juez de letras del trabajo. De no aceptarse este argumento se puede caer en el absurdo de condenar a un sujeto en virtud del inciso primero del artículo 500 del CT sin haber sido oído. La única excepción a esto, es el caso del artículo $201^{11}$.

Otra cuestión que debemos dilucidar es si es aplicable al procedimiento monitorio la situación que regulan las normas de subcontratación. En efecto, todo el articulado del Libro V del CT obedece a la dualidad "trabajador-empleador", como partes unipersonales, no como litisconsortes. Los artículos 446 No 3, 448, 449, 452, 497499 del CT son un fiel reflejo de lo que estamos analizando: el sujeto pasivo es siempre un "demandado". Por el contrario, las normas de subcontratación de los artículos 183- A y siguientes del CT se refieren a la posibilidad que la empresa principal sea solidaria o subsidiariamente responsable de las obligaciones laborales y previsionales de dar que afecten a los contratistas a favor de los trabajadores de estos. Lo que supone que frente a una obligación laboral adeudada los

${ }^{11}$ CÁRdenas PÉREz. Procedimiento monitorio laboral. Santiago: Círculo Legal Editores, 2010. 
demandados sean dos o más. No tenemos duda que el CT no ha querido dejar de lado esta situación. Nada impide que se pueda demandar a dos o más empleadores como litisconsortes $^{12}$. Lo que debemos dilucidar es si se puede demandar a más de un empleador en el procedimiento monitorio y de ser admisible esto debemos concluir, entonces, que ambos empleadores deben ser tratados desde un punto de vista procesal en igualdad de derecho procesales legales y constitucionales.

Hemos dicho más arriba que el procedimiento monitorio es un procedimiento especial, rápido, que el legislador entrega al trabajador para perseguir procesalmente -adminịtrativa y judicialmente- sumas adeudadas por un empleador o solo judicialmente en el caso del artículo 201 del CT.

Debemos afirmar que si lo adeudado son obligaciones laborales y previsionales y eventuales indemnizaciones legales que correspondan pagar por parte de un empleador que tiene la calidad de contratista o subcontratista por expresa orden legal hay solidaridad de la empresa principal o del contratista. El propio artículo 183-B del CT permite al trabajador demandar en contra de su empleador directo y en contra de todos aquellos que puedan responder de sus derechos.

Todo parece indicar que, sea un procedimiento de aplicación general o un procedimiento monitorio, el trabajador debe demandar solidariamente al empleador directo y a la empresa principal ${ }^{13}$.

Pero demandar en el procedimiento monitorio significa no solo ejercer la acción judicial monitoria ante el juez de letras del trabajo, supone también citar para el comparendo de conciliación ante la Inspección del Trabajo, porque como lo hemos afirmado reiteradamente en este trabajo, es un requisito esencial -de acuerdo al inciso primero del artículo 497 del CT- para poder pasar a la etapa judicial monitoria. Por lo tanto cuando el artículo recién citado se refiere al empleador, por aplicación de las normas de subcontratación, debe entenderse no solo el empleador directo sino también todos aquellos que puedan responder de sus derechos solidariamente de conformidad al artículo 183-B del CT.

Dijimos más arriba que el artículo 497 del CT también permite que la citación al comparendo de conciliación sea realizada por funcionario de la Inspección quien actúa en calidad de ministro de fe, para todos los efectos legales. En esta situación la notificación al empleador se materializa personalmente o se entrega a persona adulta que se encuentre en el domicilio del reclamado. Esta es justamente la forma de citación-notificación que debe utilizarse -necesariamente- en el supuesto de subcontratación, porque en el caso que hacemos mención no puede notificarse por carta certificada cuando el domicilio de la empresa principal no está señalado en el contrato firmado por el trabajador y su empleador.

\footnotetext{
${ }^{12}$ PalAVECINO CACERES. "La responsabilidad solidaria en la subcontratación laboral. Algunas consideraciones sobre su naturaleza y sus efectos", en: Revista Chileria de Derecho del Trabajo y de la Seguridad Social. Santiago: Universidad de Chile, 2010, pp. 17-27.

${ }_{13}$ Véase la Sentencia de la Corte Suprema de 25 de septiembre de 2010: “...la demanda que el trabajador pretenda enderezar en contra del dueño de la obra o faena, que no es parte en la relación laboral, no es posible de concebir en el ámbito de competencia de los Juzgados Laborales, y en el procedimiento que los rige, sino en la forma que lo plantea el inciso cuarto del ... citado artículo 183-B del Código del Trabajo, esto es cuando se le demande conjuntamente con el contratista o empleador directo, cualquiera sea la modalidad en que deba responder en definitiva".
} 
De conformidad con lo dicho, para condenar al empleador directo y a todos aquellos que puedan responder de sus derechos solidariamente, será necesario, previamente, que estos hayan sido citados al comparendo de conciliación ante la Inspección del Trabajo. Y esto es así, porque el propio artículo 500 del CT lo exige expresamente: para pronunciarse el tribunal sobre la demanda monitoria, debe considerar, entre otros antecedentes, la comparecencia de las partes en la etapa administrativa. Si el propio legislador le ordena al juez considerar la comparecencia de las partes en la etapa ante la Inspección del trabajo, es porque a lo menos exige su citación al comparendo de conciliación, citación hecha en forma legal ${ }^{14}$.

\section{BIBLIOGRAFÍA}

AYLWIN CHIORRINI. "Responsabilidad de la empresa principal por obligaciones laborales y previsionales en la subcontratación laboral" en: http://www.minjusticia.cl/laboral/andres-aylwin.pdf. -Consultado el día 18 de octubre $2010-$

CANDIA GUZMAN y KOCH CID. Reforma Procesal del Trabajo. Santiago: Editorial Metropolitana, 2009.

CÁrdenas Pérez. Procedimiento monitorio laboral. Santiago: Círculo Legal Editores, 2010.

LAURIE COFRÉ, M. El proceso monitorio, un nuevo proceso civil para el derecho chileno. Tesis. Antofagasta: Universidad Católica del Norte, 2007.

Orellana TORRES. Comentarios al nuevo proceso laboral. Santiago: Librotecnia, 2009.

PALAVECINO CÁCERES. Subcontratación. Régimen Jurídico del trabajo subcontratado y del suministro del personal -reimpresión-. Santiago: Editorial Jurídica de Chile, 2010.

PALAVECINO CACERES. "La responsabilidad solidaria en la subcontratación laboral. Algunas consideraciones sobre su naturaleza y sus efectos", en: Revista Chilena de Derecho del Trabajo y de la Seguridad Social. Santiago: Universidad de Chile, 2010.

PEREIRA LAGOS. El procedimiento monitorio laboral. Santiago: Legal Publishing, 2010.

PÉREZ RAGONE, A. "En torno al procedimiento monitorio desde el derecho procesal comparado europeo", en: Revista de Derecho vol. 19, n. 1. Valdivia: Universidad Austral, 2006.

Walter Dfaz y Lanata Fuenzalida. Régimen Legal del nuevo proceso laboral chileno. Santiago: Legal Publishing, 2009.

\footnotetext{
${ }^{14}$ AYLWIN CHIORRINI. "Responsabilidad de la empresa principal por obligaciones laborales y previsionales n la subcontratación laboral" en: http://www.minjusticia.cl/laboral/andres-aylwin.pdf. -Consultado el día 18 de octubre 2010-.
} 